This paper is part of the Proceedings of the $3^{\text {rd }}$ International Conference on Design, Construction, Maintenance, Monitoring and Control of Urban Water Systems

\title{
Laboratory study on the rainfall influence over the sediment transport dynamics on pervious pavements' discharge
}

\author{
M. Marchioni ${ }^{1}$, V. C. Andrés-Valeri ${ }^{2}$, F. Giustozzi ${ }^{1}$ \& G. Becciu ${ }^{1}$ \\ ${ }^{I}$ Politecnico di Milano, Italia \\ ${ }^{2}$ Universidad de Cantabria, España
}

\begin{abstract}
Infiltration capacity reduction due to the progressive clogging of land surfaces is the most important feature controlling pervious pavement life use. It is influenced by material and local characteristics. The rainfall regime can be influenced by water volume and rainfall intensity. A laboratory study was conducted to analyze the influence of the rainfall intensity on the sediments dynamics on pervious pavements. Three different rainfall intensities were settled using a rainfall simulator: $50 \mathrm{~mm} / \mathrm{h}, 100 \mathrm{~mm} / \mathrm{h}$ and $150 \mathrm{~mm} / \mathrm{h}$. Pervious concrete (PC) and porous asphalt (PA) slabs of $50 \times 26 \times 5 \mathrm{~cm}$, with void contents of $15 \%, 20 \%$ and $25 \%$ were tested. They were clogged using sediments containing mostly sand and an assembled PSD (particle size distribution) that fall within the range of real case scenarios. The sediments were applied over the slabs on aerial loadings of $0.5 \mathrm{~kg} / \mathrm{m}^{2}, 1.0 \mathrm{~kg} / \mathrm{m}^{2}$ and $2.0 \mathrm{~kg} / \mathrm{m}^{2}$. Using a falling head permeameter discharge measurements were made over the samples in newly built conditions, after clogging and after rainfall simulation. The obtained results showed that in most cases the rainfall intensity does not produce significant differences in discharge time. The information obtained through this study provides better understanding of sediments transport mechanisms on pervious pavements and could lead to customized maintenance routines.
\end{abstract}

Keywords: pervious pavement, clogging, rainfall simulation, sustainable urban drainage. 


\section{Introduction}

Pervious pavements are part of sustainable drainage systems (SUDs) and promote storm water volume and pollutants control (Marchioni and Becciu [1]). The open porosity matrix allows water to infiltrate although at the same time it behaves like a filter, promoting particulate matter (PM) separation. Although this particular feature is essential to promote water quality improvement, it also reduces the infiltration capacity of the pavement at the point that maintenance or rehabilitation is needed (Sansalone et al. [2]).

The infiltration capacity reduction of pervious pavement systems will basically depends upon the material characteristics (void content, hydraulic conductivity,

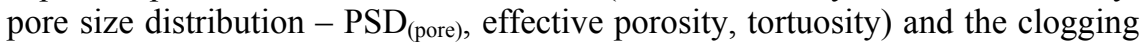
sediment properties (loading, particle size distribution - PSD). There is also local influence of local features, like the average daily traffic, the rainfall regime and presence of vegetated areas ( $\mathrm{Li}$ et al. [3]). Depending on the rainfall characteristics, the sediments deposited over the pavement surface could be washed off, partially recovering the infiltration capacity, or consolidated due to the impact of the rain drops, decreasing the infiltration capacity of the pavement. Accurately knowing how long it takes for the pavement to fall below an accepted level of infiltration allows for better scheduling of maintenance and better evaluation of costs over the service life.

\section{Objective}

The objective of this study is to investigate the rainfall intensity influence over pervious surfaces using a laboratory rainfall simulation device.

\section{Materials and methods}

\subsection{Pervious concrete}

Nine pervious concrete slabs were produced with $50 \times 26 \times 5 \mathrm{~cm}$ of dimension. The concrete mix design was obtained according to a previous study from (Bonicelli et al. [4]). The mix design contained a 2-12 $\mathrm{mm}$ limestone coarse aggregate, and $5 \%$ by weight of coarse aggregates of quarry sand. It was used a type II CEM II 42.5R A-LL Portland cement with limestone addition with a water to cement ratio $(w / c)$ of 0.27 and a cement to aggregate ratio $(a / c)$ of 0.2 . Three different admixtures were used: high range water reducer, air-entraining admixture and viscosity-modifying admixture with the dosages recommended by the manufacturers. The slabs were manually compacted with the help of a Marshall test device. By controlling the mass of concrete in a specific volume three slabs were produced for each void content: $15 \%, 20 \%$ and $25 \%$.

\subsection{Porous asphalt}

We also produced nine slabs of porous asphalt with $50 \times 26 \times 5 \mathrm{~cm}$ of dimensions. The porous asphalt mixture contained $4.1 \%$ by weight of mixture of SBS (Styrene- 
Butadiene-Styrene) modified bitumen and the slabs were compacted using a wheel tracking device to obtain the void contents of $15 \%, 20 \%$ and $25 \%$.

\subsection{Clogging sediments loadings}

Sand and recovery filler were mixed to achieve a PSD distribution with maximum density according to particle size packing theories. This PSD distribution was then compared to dry deposition PSD obtained in the literature (Deletic and Orr [5]) (Zafra et al. [6]) (Bian and Zhu [7]) to guarantee that the material fell within their limits.

\subsection{Falling head permeameter}

A falling head permeameter according to EN 12697-19 was used to measure the water flow on the slabs. A similar device, the LCS (Laboratorio de Caminos de Santander) permeameter have already been used to investigate the decaying of infiltration capacity on pervious surfaces (Jimenez and Perez [8]) (SañudoFontaneda et al. [9]). This field falling head permeameter measures drainage capacity $\left(\mathrm{dm}^{3} / \mathrm{min}\right)$ and is not suitable to obtain the hydraulic conductivity using Darcy's Law (Ranieri et al. [10]). In this work the discharge time was measured, i.e., the time the falling water column falls $20 \mathrm{~cm}$, to obtain a qualitative analysis of the behaviour of the slab regarding infiltration capacity. When the discharge time reach $300 \mathrm{~s}$ the slab was considered fully clogged and the test stopped. All tests were conducted on three points of the slabs.

\subsection{Rainfall simulator}

A rainfall simulator was developed to investigate the behaviour of runoff over the pervious surfaces under clogged conditions. The device consisted of a $3 \mathrm{~m}$ high steel structure with 30 droppers placed on top. The slabs were placed $60 \mathrm{~cm}$ over the ground and in between the droppers and the slabs were placed framed nets to distribute the raindrops. The droppers were feed by a plastic tube connected to a flow meter with $2-30 \mathrm{l} / \mathrm{h}$ capacity. The rainfall simulator allows to simulate rainfall intensities ranging from $25 \mathrm{~mm} / \mathrm{h}$ to $200 \mathrm{~mm} / \mathrm{h}$. The flour pellet method was used to measure the drop distribution and assure they respect the dimension of natural rainfall drops (Hudson and Rhodesia [11]).

\subsection{Rainfall simulation tests}

Using the rainfall simulator the 18 slabs of pervious concrete and porous asphalt were tested using rainfall intensities of $50 \mathrm{~mm} / \mathrm{h}, 100 \mathrm{~mm} / \mathrm{h}$ and $150 \mathrm{~mm} / \mathrm{h}$ and aerial loading of sediments of $0.5 \mathrm{~kg} / \mathrm{m}^{2}, 1.0 \mathrm{~kg} / \mathrm{m}^{2}$ and $2.0 \mathrm{~kg} / \mathrm{m}^{2}$ in a total of 162 tests. The test consisted in placing the slab on the rainfall simulator, manually adding the load of sediment over the slab and starting 15 minutes of rainfall on the chosen intensity. After the 15 minutes the rainfall stopped, the runoff mass was collected on a small container and the discharge time was measured with the falling head permeameter. 


\section{Results and discussion}

\subsection{Preliminary results}

Prior of conducting rainfall simulation tests the discharge times were measured with and without load of sediments according to Figure 1 for PC and Figure 2 for PA. As expected for a heterogeneous material the discharge time results were highly disperse, as can be observed through the overlapping errors bars in Figures 1 and 2 and in Table 1.

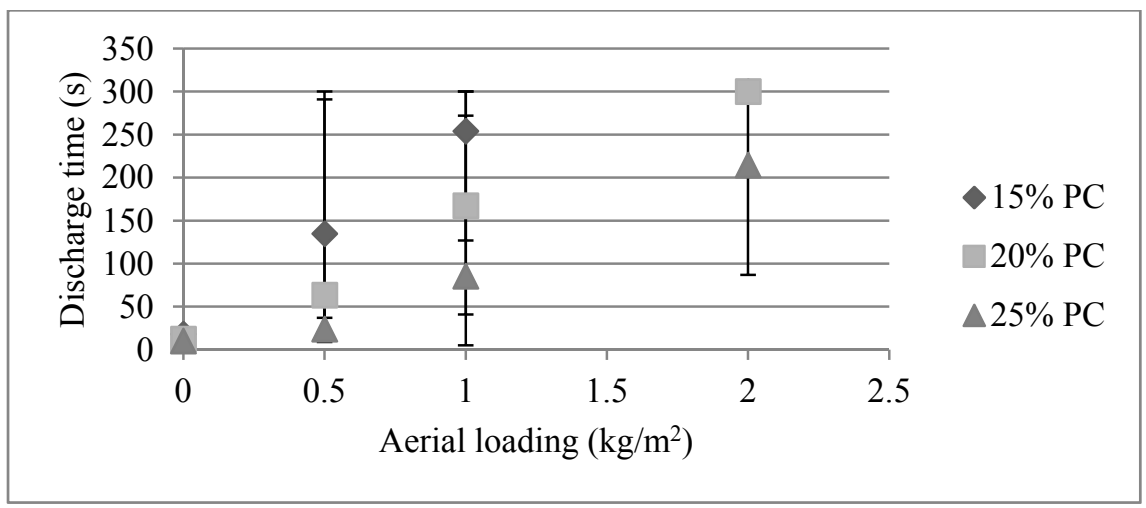

Figure 1: $\quad$ PC initial discharge times.

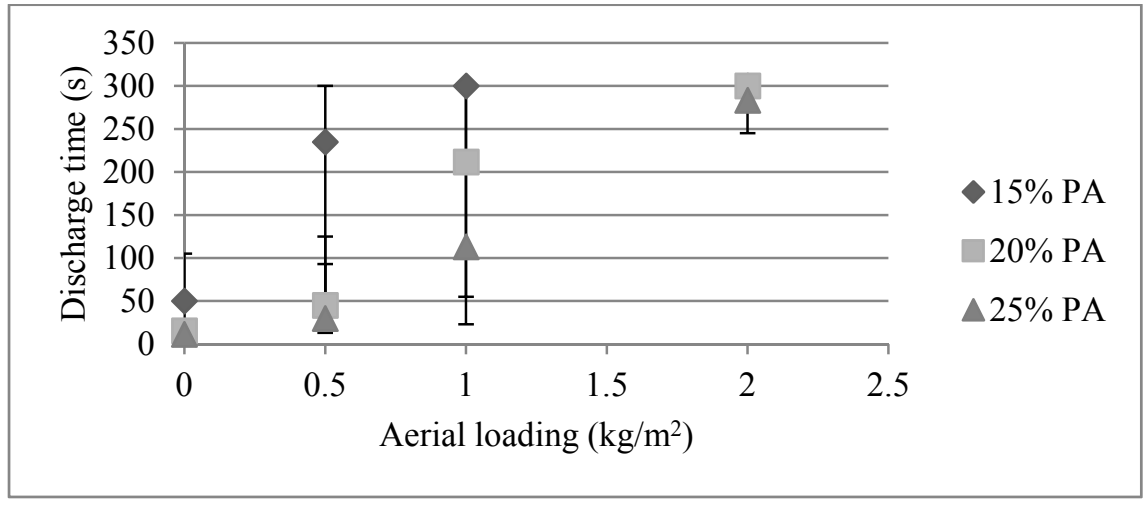

Figure 2: $\quad$ PA initial discharge times.

For this reason the results obtained were analysed in order to assess the statistical significance of the differences observed depending on the void contents of the materials for the different clogging scenarios. The non-parametric KruskalWallis H-test was used to compare the PC and PA discharge time results for the three void contents. The results of this test showed that there were significant differences among the discharge times measured for the different air void contents 
for both pervious concrete ( $\mathrm{p}$-value $=0.0014)$ and porous asphalt $(\mathrm{p}$-value $=3.68 \times$ $10^{-5}$ ) considering a $99 \%$ confidence level. Therefore a statistically significant difference was observed for discharge times when varying the void content.

Table 1: $\quad$ Initial discharge times for the PC and PA slabs.

\begin{tabular}{|c|c|c|c|c|c|c|}
\hline Type & $\begin{array}{c}\text { Void } \\
\text { content }\end{array}$ & $\begin{array}{c}\text { Aerial } \\
\text { loading } \\
\left(\mathrm{kg} / \mathrm{m}^{2}\right)\end{array}$ & $\begin{array}{c}\operatorname{AVR}^{(1)} \\
(\mathrm{s})\end{array}$ & $\begin{array}{l}\operatorname{STD}^{(2)} \\
\operatorname{dev}(s)\end{array}$ & $\begin{array}{l}\text { Maximum } \\
\text { value (s) }\end{array}$ & $\begin{array}{l}\text { Minimum } \\
\text { value(s) }\end{array}$ \\
\hline \multirow[t]{12}{*}{$\mathrm{PC}$} & 15 & 0 & 18 & 2 & 21 & 15 \\
\hline & 15 & 0.5 & 135 & 108 & 300 & 37 \\
\hline & 15 & 1 & 254 & 60 & 300 & 127 \\
\hline & 15 & 2 & 300 & 0 & 300 & 300 \\
\hline & 20 & 0 & 12 & 2 & 16 & 9 \\
\hline & 20 & 0.5 & 63 & 83 & 291 & 20 \\
\hline & 20 & 1 & 167 & 103 & 300 & 41 \\
\hline & 20 & 2 & 300 & 0 & 300 & 300 \\
\hline & 25 & 0 & 10 & 3 & 14 & 5 \\
\hline & 25 & 0.5 & 24 & 12 & 50 & 9 \\
\hline & 25 & 1 & 85 & 85 & 272 & 5 \\
\hline & 25 & 2 & 215 & 90 & 300 & 87 \\
\hline \multirow[t]{12}{*}{ PA } & 15 & 0 & 50 & 24 & 105 & 20 \\
\hline & 15 & 0.5 & 235 & 92 & 300 & 41 \\
\hline & 15 & 1 & 300 & 0 & 300 & 300 \\
\hline & 15 & 2 & 300 & 0 & 300 & 300 \\
\hline & 20 & 0 & 15 & 3 & 19 & 10 \\
\hline & 20 & 0.5 & 45 & 29 & 125 & 22 \\
\hline & 20 & 1 & 211 & 86 & 300 & 55 \\
\hline & 20 & 2 & 300 & 0 & 300 & 300 \\
\hline & 25 & 0 & 11 & 3 & 18 & 8 \\
\hline & 25 & 0.5 & 30 & 25 & 93 & 13 \\
\hline & 25 & 1 & 113 & 102 & 300 & 23 \\
\hline & 25 & 2 & 283 & 24 & 300 & 245 \\
\hline
\end{tabular}

${ }^{(1)}$ Average; ${ }^{(2)}$ Standard deviation.

An exponential behaviour was observed for the average discharge as function of the sediments aerial loadings. To model that behaviour a first order exponential model was used (eqn (1)), where $d$ is the discharge, 1 is the sediments aerial loadings, and $\mathrm{a}$ and $\mathrm{b}$ are constants. The coefficients of determination $\mathrm{R}^{2}$ for the PC samples of $15 \%, 20 \%$ and $25 \%$ of void content are respectively of $0.74,0.93$ and 0.98 . For the PA samples of $15 \%, 20 \%$ and $25 \%$ of void content the $\mathrm{R}^{2}$ is respectively of $0.53,0.82$ and 0.97 .

$$
\mathrm{d}(1)=\mathrm{a}^{\mathrm{x}} \cdot \mathrm{e}^{\mathrm{b} \cdot \mathrm{x}}
$$


The modelled equation was used to quantify the sediments loads necessary to fully clog the slabs. It was obtained that to reach fully clogged stage on PC it was necessary $1.8 \mathrm{~kg} / \mathrm{m}^{2}$ of loadings for the $15 \%$ void content, $2.0 \mathrm{~kg} / \mathrm{m}^{2}$ for $20 \%$ void content and $2.3 \mathrm{~kg} / \mathrm{m}^{2}$ for $25 \%$ void content. For the PA it was necessary $1.01 \mathrm{~kg} / \mathrm{m}^{2}$ of loadings for the $15 \%$ void content, $1.95 \mathrm{~kg} / \mathrm{m}^{2}$ for $20 \%$ void content and $2.04 \mathrm{~kg} / \mathrm{m}^{2}$ for $25 \%$ void content.

On this study the PC showed a higher infiltration capacity in general when compared with the PA. This difference can be result of the difference on PSD of the aggregates used and the compaction methods. Further analysis is needed to investigate the pore properties of the materials (total porosity, effective porosity, $\operatorname{PSD}_{(\text {pore) }}$, pore connective, tortuosity) to understand the difference on the results.

\subsection{Rainfall intensity impact on sediment transportation}

\subsubsection{PC results}

In Figure 3, the PC tests held with the rainfall simulator in comparison with the initial test without rainfall are plotted. The data plotted is average and the error bars shown the maximum and minimum values. Statistical analysis was held to confirm if there were statistically significant different for the results obtained for each aerial loading group by using the Kruskal-Wallis H-test (Table 2). For the void contents of $20 \%$ and $25 \%$, and aerial loading of $0.5 \mathrm{~kg} / \mathrm{m}^{2}$ and $1.0 \mathrm{~kg} / \mathrm{m}^{2}$ there were not significant difference between samples with $99 \%$ of confidence level. That means that for these tests the rainfall intensities did not produce significant changes on sediment transportation and did not result on significant changes on discharge times. For the samples that result different, multiple pairwise comparison were performed by using the non-parametric Mann-Whitney U-Test (Wilcoxon Rank Sum Test) with a confidence level of 95\% (Table 3).

Analysing the PC results it can be observed a significant variation of the discharge time for all tests with rainfall of $150 \mathrm{~mm} / \mathrm{h}$ and aerial loadings of $2 \mathrm{~kg} / \mathrm{m}^{2}$. For that sediment loadings the surfaces were completely clogged for the $20 \%$ and $25 \%$ void content and after the rainfall simulations they shown a reduction on discharge time going from $300 \mathrm{~s}$ to $125 \mathrm{~s}$ and $201 \mathrm{~s}(33 \%$ and $58 \%$ of reduction) respectively, on average. For the $25 \%$ void content the reduction was from $215 \mathrm{~s}$ to $72 \mathrm{~s}, 66 \%$ of reduction on average. Therefore a rainfall effect over the sediments transportation is clearly notice on high intensities rainfall and clogged or almost clogged situation. In Milan's case (North of Italy) a rainfall with $150 \mathrm{~mm} / \mathrm{h}$ of intensity and 15 minutes of duration will have a return period of 50 years (Becciu and Paoletti [12]). 


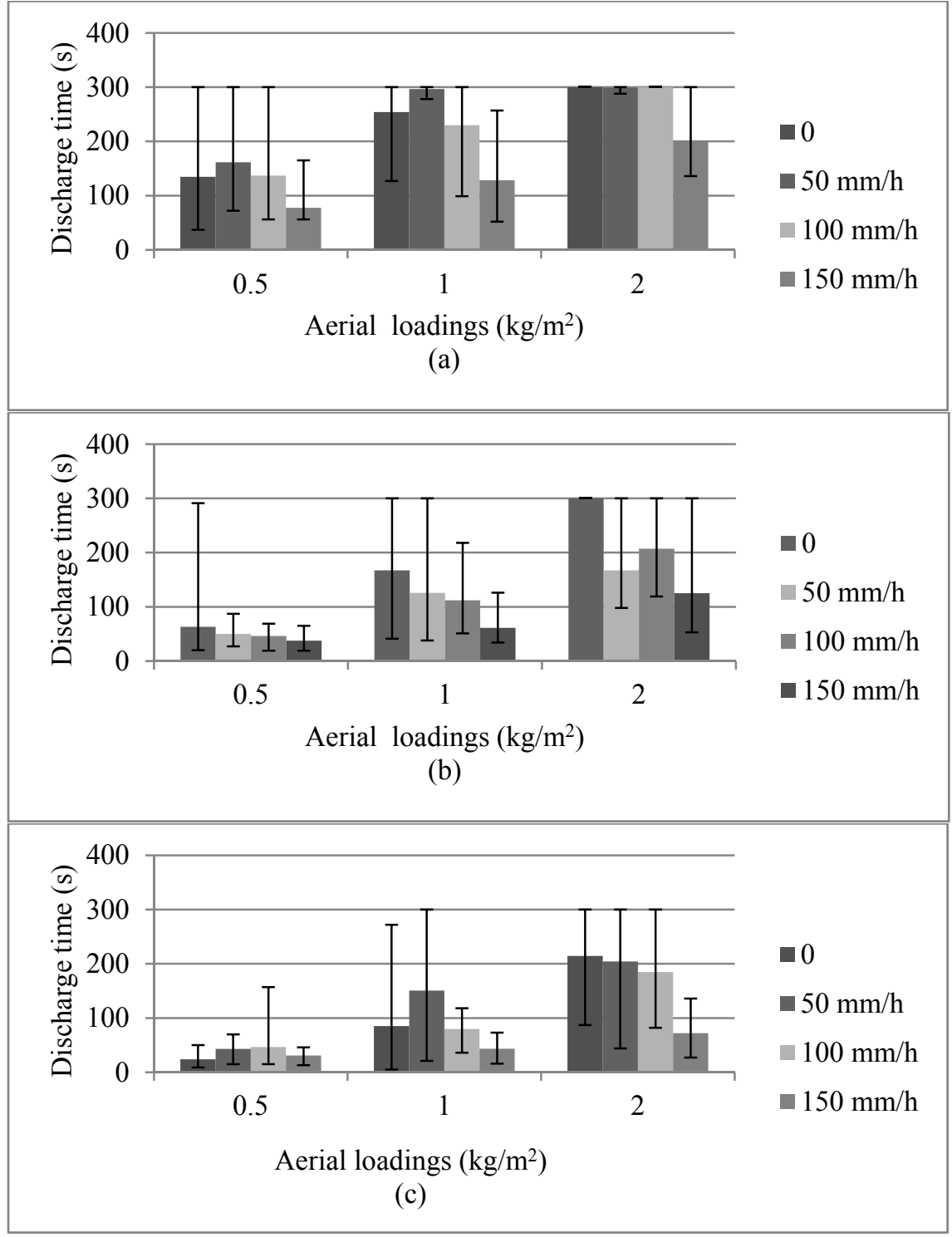

Figure 3: $\quad$ PC discharge time measured after rainfall simulation tests with aerial loadings ranging from $0.5 \mathrm{~kg} / \mathrm{m}^{2}$ to $2.0 \mathrm{~kg} / \mathrm{m}^{2}$ and rainfall intensities ranging from $50 \mathrm{~mm} / \mathrm{h}$ and $150 \mathrm{~mm} / \mathrm{h}$ compared to the preliminary tests without rainfall. $(a)=15 \%$ void content, $(b)=20 \%$ void content and $(\mathrm{c})=25 \%$ void content. 
Table 2: $\quad$ PC statistical analysis on the same void content and aerial loading group.

\begin{tabular}{|c|c|c|c|}
\hline Void Content (\%) & Aerial Loading $\left(\mathrm{kg} / \mathrm{m}^{2}\right)$ & $\mathrm{p}^{(1)}$ & $\mathrm{p}>0.01$ \\
\hline 15 & 0.5 & 0.005 & false \\
\hline 15 & 1 & 0.001 & false \\
\hline 15 & 2 & 0.003 & false \\
\hline $\mathbf{2 0}$ & $\mathbf{0 . 5}$ & $\mathbf{0 . 4 0 9}$ & true \\
\hline $\mathbf{2 0}$ & $\mathbf{1}$ & $\mathbf{0 . 0 4 8}$ & true \\
\hline 20 & 2 & 0.001 & false \\
\hline $\mathbf{2 5}$ & $\mathbf{0 . 5}$ & $\mathbf{0 . 1 2 1}$ & true \\
\hline $\mathbf{2 5}$ & $\mathbf{1}$ & $\mathbf{0 . 1 8 0}$ & true \\
\hline 25 & 2 & 0.003 & false \\
\hline
\end{tabular}

${ }^{(1)} \mathrm{p}$-value for the null hypothesis that the tested data comes from the same distribution, using a Kruskal-Wallis test. The alternative hypothesis is that not all samples come from the same distribution.

Table 3: $\quad$ PC statistical analysis comparing discharge time for different rainfall intensities.

\begin{tabular}{|c|c|c|c|c|c|}
\hline $\begin{array}{c}\text { Void content } \\
(\%)\end{array}$ & $\begin{array}{c}\text { Rainfall intensity } \\
(\mathrm{mm} / \mathrm{h})\end{array}$ & $\begin{array}{c}\text { Aerial } \\
\text { loading } \\
\left(\mathrm{kg} / \mathrm{m}^{2}\right)\end{array}$ & $\mathrm{p}^{(1)}$ & $\mathrm{p}>0.05$ & $\begin{array}{c}\text { Rank } \\
\text { sum }\end{array}$ \\
\hline 15 & $0 \times 50$ & 0.5 & 0.339 & true & 74 \\
\hline 15 & $0 \times 100$ & 0.5 & 0.055 & true & 64 \\
\hline 15 & $0 \times 150$ & 0.5 & 0.983 & true & 87 \\
\hline 15 & $0 \times 50$ & 1 & 0.164 & true & 72.5 \\
\hline 15 & $0 \times 100$ & 1 & 0.520 & true & 92.5 \\
\hline $\mathbf{1 5}$ & $\mathbf{0} \times \mathbf{1 5 0}$ & $\mathbf{1}$ & $\mathbf{0 . 0 0 2}$ & false & $\mathbf{1 1 9}$ \\
\hline 15 & $0 \times 50$ & 2 & 1.000 & true & 90 \\
\hline 15 & $0 \times 100$ & 2 & 0.082 & true & 103.5 \\
\hline $\mathbf{1 5}$ & $\mathbf{0} \times \mathbf{1 5 0}$ & $\mathbf{2}$ & $\mathbf{0 . 0 0 2}$ & false & $\mathbf{1 1 7}$ \\
\hline $\mathbf{2 0}$ & $\mathbf{0} \times \mathbf{5 0}$ & $\mathbf{2}$ & $\mathbf{0 . 0 0 2}$ & false & $\mathbf{1 1 7}$ \\
\hline $\mathbf{2 0}$ & $\mathbf{0} \times \mathbf{1 0 0}$ & $\mathbf{2}$ & $\mathbf{0 . 0 0 9}$ & false & $\mathbf{1 1 2 . 5}$ \\
\hline $\mathbf{2 0}$ & $\mathbf{0} \times \mathbf{1 5 0}$ & $\mathbf{2}$ & $\mathbf{0 . 0 0 0}$ & false & $\mathbf{1 2 1 . 5}$ \\
\hline 25 & $0 \times 50$ & 2 & 0.675 & true & 90.5 \\
\hline 25 & $0 \times 100$ & 2 & 0.468 & true & 94 \\
\hline $\mathbf{2 5}$ & $\mathbf{0} \times \mathbf{1 5 0}$ & $\mathbf{2}$ & $\mathbf{0 . 0 0 1}$ & false & $\mathbf{1 2 1 . 5}$ \\
\hline
\end{tabular}

${ }^{(1)} \mathrm{p}=$ Rank sum test returns the $\mathrm{p}$-value of a two-sided Wilcoxon rank sum test. The null hypothesis is that the two samples data are from continuous distributions with equal medians, against the alternative that they are not.

\subsubsection{PA results}

The same analyses were held for the PA data. In Figure 4 the discharge times varying the rainfall intensities for each group of void content and aerial loadings are shown. Then in Table 4 the groups with the same void content and aerial 
loading were compared using the Kruskal-Wallis H-test to inquiry if they were significant different with $99 \%$ of confidence level.

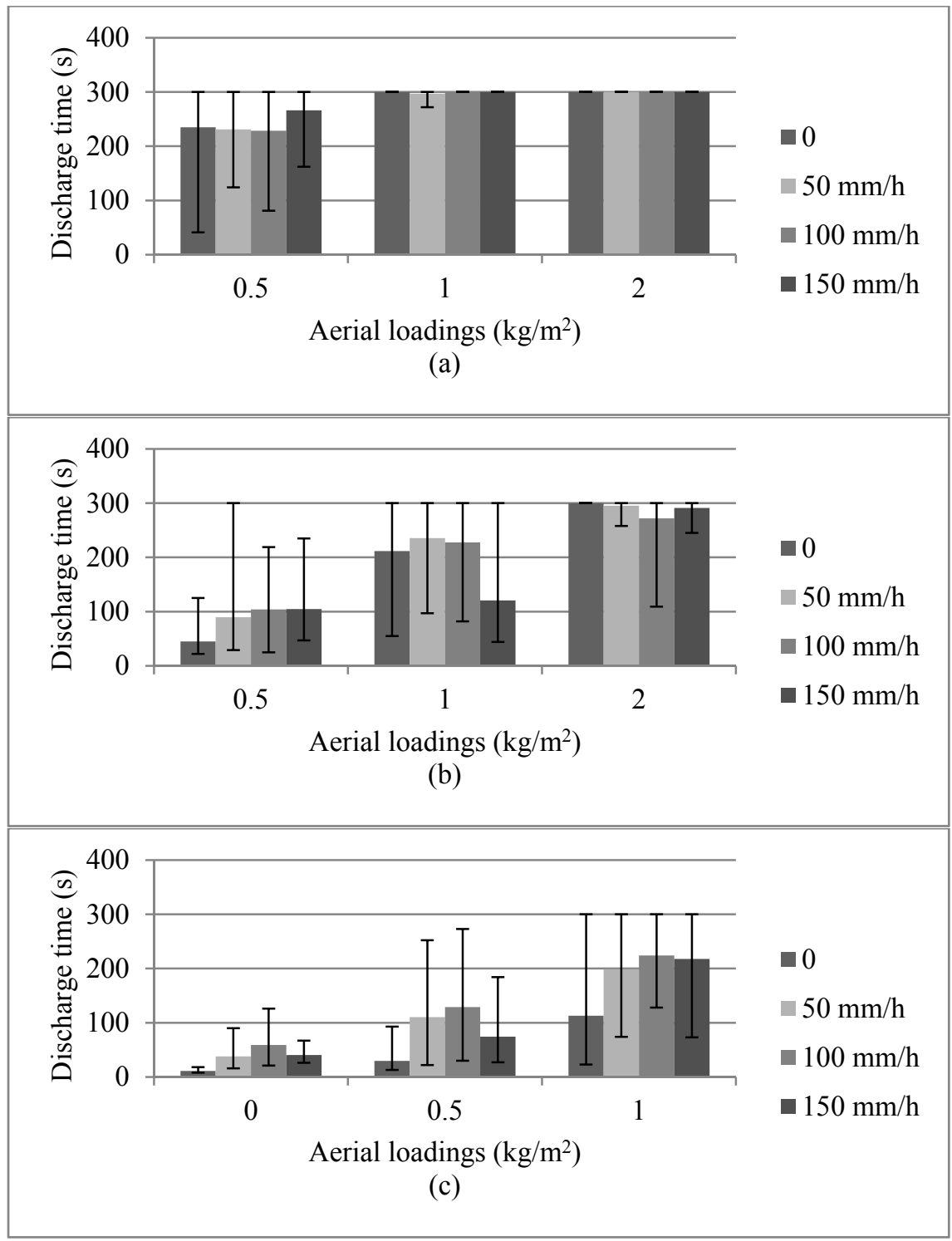

Figure 4: $\quad$ PA discharge time measured after rainfall simulation tests with aerial loadings ranging from $0.5 \mathrm{~kg} / \mathrm{m}^{2}$ to $2.0 \mathrm{~kg} / \mathrm{m}^{2}$ and rainfall intensities ranging from $50 \mathrm{~mm} / \mathrm{h}$ and $150 \mathrm{~mm} / \mathrm{h}$ compared to the preliminary tests without rainfall. (a) $=15 \%$ void content, (b) $=20 \%$ void content and $(\mathrm{c})=25 \%$ void content. 
Table 4: $\quad$ PA statistical analysis on the same void content and aerial loading group.

\begin{tabular}{|c|c|c|c|}
\hline Void content (\%) & Aerial loading $\left(\mathrm{kg} / \mathrm{m}^{2}\right)$ & $\mathrm{p}^{(1)}$ & $\mathrm{p}>0.01$ \\
\hline 15 & 0.5 & 0.883 & true \\
\hline 15 & 1 & 0.392 & true \\
\hline 15 & 2 & $-(2)$ & - \\
\hline 20 & 0.5 & 0.022 & true \\
\hline 20 & 1 & 0.040 & true \\
\hline 20 & 2 & 0.457 & true \\
\hline 25 & 0.5 & 0.057 & true \\
\hline 25 & 1 & 0.371 & true \\
\hline 25 & 2 & 0.107 & true \\
\hline
\end{tabular}

(1) $\mathrm{p}$-value for the null hypothesis that the tested data comes from the same distribution, using a Kruskal-Wallis test. The alternative hypothesis is that not all samples come from the same distribution.

${ }^{(2)}$ For the $15 \%$ void content with $2.0 \mathrm{~kg} / \mathrm{m}^{2}$ of sediments all the discharge times reached the maximum limit of $300 \mathrm{~s}$.

The analysis on the PA samples did not find statistically significant difference between the discharge time when varying the rainfall intensities for the same void content and aerial loading of sediments. Therefore the event of rainfall does not produce visible differences on discharge on the PA slabs. This result, which does not follow what was observed on the PC, can also be explained for the differences on the porous properties and further analysis should be conducted.

\subsection{Runoff coefficient}

The runoff coefficient was also analysed after all rainfall simulation tests. On PC the maximum value for runoff was $1.78 \%$ for a slab with $15 \%$ void content clogged with $2 \mathrm{~kg} / \mathrm{m}^{2}$ of sediments under a $150 \mathrm{~mm} / \mathrm{h}$ rainfall intensity. On $69 \%$ of PC rainfall simulation tests any runoff was not observed (runoff coefficient $=0$ ).

For the PA the maximum value of runoff was $12.64 \%$ for a slab with $15 \%$ void content, clogged with $2 \mathrm{~kg} / \mathrm{m}^{2}$ of sediments under a $100 \mathrm{~mm} / \mathrm{h}$ rainfall intensity. For $38 \%$ of PA tests, there was no observed runoff (runoff coefficient $=0$ ) and $74 \%$ of the tests showed runoff coefficients below $1.0 \%$.

In both cases the value for runoff coefficient is significantly lower than a conventional pavement, which can reach over than $90 \%$ runoff coefficient (de Araújo et al. [13]). It was observed that even in the cases that the slabs were completely clogged, i.e., showing a $300 \mathrm{~s}$ discharge time, the runoff coefficient remained low, meaning that the pervious pavement was still functional. The probable reason is that the rough surface reduced the runoff velocity at the point that allowed infiltration as it was observed on previous research (RodriguezHernandez et al. [14]). All the tests were conducted with a $2.5 \%$ slope and an increase on slope could eventually lead to higher runoff. The variations held on 
the tests (void content, rainfall intensities, sediments concentration) did not produce significant differences on the runoff results.

\section{Conclusions}

Under the conditions of this study the rainfall intensity had no or little effect on the sediments transportation over the surface of the pervious pavement and therefore does not produce significantly different effects on the pavement. Additionally, when modelling the infiltration capacity decay, in this case represented by the increase of discharge time, the effect of rainfall intensity may be disregarded within the constraints present here. However, being the sediment PSD and pervious surfaces PSD $_{\text {(pore) }}$ the main elements of influence on the clogging process, variation on these elements could lead to changes regarding the influence of rainfall.

One interesting point on this study was that even during fully clogged discharge times the runoff volume was significantly low, hence the pavement was still functional for the runoff reduction volume property.

This project following steps consists on evaluate the pore properties of both PC and PA samples and determine the hydraulic conductivity $\left(\mathrm{K}_{\mathrm{d}}\right)$ through the Darcy's Law, to be able to model the hydraulic and pollution removal. Also by relating the sediments loadings with real case scenarios the discharge decay can be related with a time period and provide a maintenance schedule under the materials and local conditions.

\section{Acknowledgements}

We appreciate the efforts of the engineer Matteo Brugin with the rainfall simulation tests and the support of the "Gaudenzio Fantoli" Hydraulics Laboratory and the Experimental Roadway Laboratory of the Politecnico di Milano and their staff. Mariana Marchioni would like to thanks Capes for funding this work through the scholarship number BEX 9224/13-0 as part of the Ciências sem Fronteiras program. Valerio C. Andrés-Valeri would like to thanks the Spanish Ministry of Economy and Competitiveness, funding for his research activity in the Politecnico di Milano through the PhD fellowship (BES-2013-062604), and the mobility grant (EEBB-I-15-10095).

\section{References}

[1] Marchioni, M. and G. Becciu, Experimental Results On Permeable Pavements In Urban Areas: A Synthetic Review. International Journal of Sustainable Development and Planning, 2015. 10(6): pp. 806-817.

[2] Sansalone, J., et al., Filtration and clogging of permeable pavement loaded by urban drainage. Water Research, 2012. 46(20): pp. 6763-6774. 
[3] Li, H., M. Kayhanian, and J.T. Harvey, Comparative field permeability measurement of permeable pavements using ASTM C1701 and NCAT permeameter methods. Journal of Environmental Management, 2013. 118(0): pp. 144-152.

[4] Bonicelli, A., F. Giustozzi, and M. Crispino, Experimental study on the effects of fine sand addition on differentially compacted pervious concrete. Construction and Building Materials, 2015. 91: pp. 102-110.

[5] Deletic, A. and D.W. Orr, Pollution buildup on road surfaces. Journal of Environmental Engineering, 2005. 131(1): pp. 49-59.

[6] Zafra, C., J. Temprano, and I. Tejero, Particle size distribution of accumulated sediments on an urban road in rainy weather. Environmental technology, 2008. 29(5): pp. 571-582.

[7] Bian, B. and W. Zhu, Particle size distribution and pollutants in roaddeposited sediments in different areas of Zhenjiang, China. Environmental geochemistry and health, 2009. 31(4): pp. 511-520.

[8] Jimenez, F.P. and M.C. Perez, Analysis and evaluation of the performance of porous asphalt: the Spanish experience, in Surface characteristics of roadways: International research and technologies. 1990, ASTM International.

[9] Sañudo-Fontaneda, L.A., et al., Field study of infiltration capacity reduction of porous mixture surfaces. Water, 2014. 6(3): pp. 661-669.

[10] Ranieri, V., et al., Measurement of Hydraulic Conductivity in Porous Mixes. Transportation Research Record: Journal of the Transportation Research Board, 2012(2295): pp. 1-10.

[11] Hudson, N.W. and S. Rhodesia, The flour pellet method for measuring the size of raindrops. 1964: Department of Conservation and Extension.

[12] Becciu, G. and A. Paoletti, Fondamenti di costruzioni idrauliche. 2010: Utet Scienze tecniche.

[13] de Araújo, P.R., C.E. Tucci, and J.A. Goldenfum, Avaliação da eficiência dos pavimentos permeáveis na redução de escoamento superficial. 2000.

[14] Rodriguez-Hernandez, J., et al., Characterization of infiltration capacity of permeable pavements with porous asphalt surface using cantabrian fixed infiltrometer. Journal of Hydrologic Engineering, 2011. 17(5): pp. 597-603. 